\title{
Addition of vasodilators to diuretic therapy does not improve outcome in acute heart failure
}

When given at low doses in conjunction with diuretic therapy, neither dopamine nor nesiritide improves decongestion or renal function in patients with acute decompensated heart failure. These disappointing findings from the ROSE study were presented at the 2013 AHA Scientific Sessions and published in JAMA. "The current findings differ from those of previous small studies that suggested the benefits of low-dose dopamine in acute heart failure," write the investigators.

\section{4 ...the coprimary end points ... did not differ between study drug and placebo for either dopamine or nesiritide 77}

The ROSE study included 302 patients hospitalized with acute heart failure, who also had renal dysfunction (glomerular filtration rate $15-60 \mathrm{ml} / \mathrm{min} / 1.73 \mathrm{~m}^{2}$ ). Participants were randomly assigned first (1:1) to the low-dose dopamine $(2 \mu \mathrm{g} / \mathrm{kg} / \mathrm{min})$ or the low-dose nesiritide $(0.005 \mu \mathrm{g} / \mathrm{kg} / \mathrm{min})$ arm of the trial, and then (2:1) to receive either study drug or placebo for $72 \mathrm{~h}$. All patients received loop diuretics. The median left ventricular ejection fraction was $33 \%$, and $26 \%$ of patients had preserved ( $>50 \%$ ) ejection fraction.

At $72 \mathrm{~h}$ after initiation of treatment, the coprimary end points of cumulative urine volume (efficacy of decongestion) and change in cystatin $\mathrm{C}$ level from baseline (renal function) did not differ between study drug and placebo for either dopamine or nesiritide. No treatment-related deaths occurred, and the rate of treatment failure did not differ significantly between the groups. No differences in clinical outcomes at 60 days were observed, but the study was not sufficiently powered to evaluate these end points. Among patients with preserved ejection fraction, those who received dopamine produced less urine over $72 \mathrm{~h}$ than those receiving placebo (mean $7.26 \mathrm{ml}$ vs $9.10 \mathrm{ml} ; P=0.01)$. Although the investigators caution that "these observations may be due to chance," they suggest that "further investigation of these or other acute heart failure therapies may need to assess the potential for differential responses in heart failure [with] preserved vs reduced ejection."

In his discussion of the study at the AHA Scientific Sessions, Marco Metra from the University of Bescia, Italy (who was not involved in the trial) questioned whether such low-doses of dopamine or nesiritide could be 'renal specific'. Ultimately, the search continues for agents that will improve outcomes for patients with acute heart failure and renal dysfunction.

\section{Alexandra Roberts}

Original article Chen, H. H. et al. Low-dose dopamine or low-dose nesiritide in acute heart failure with renal dysfunction. The ROSE acute heart failure randomized trial. JAMA doi:10.1001/jama.2013.282190 